\title{
A high-efficiency Agrobacterium-mediated transient expression system in the leaves of Artemisia annua L.
}

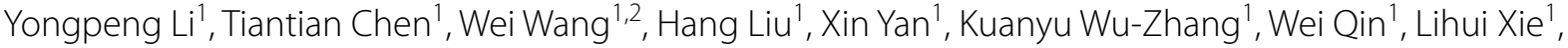 \\ Yaojie Zhang ${ }^{1}$, Bowen Peng ${ }^{1}$, Xinghao Yao ${ }^{1}$, Chen Wang ${ }^{1}$, Sadaf-llyas Kayani ${ }^{1}$, Xueqing Fu' ${ }^{1}$, Ling Li ${ }^{1}$ and \\ Kexuan Tang ${ }^{1 *}$ (i)
}

\begin{abstract}
Background: The Agrobacterium-mediated transient transformation, which proved effective in diverse plant species, has been widely applied for high-throughput gene function studies due to its simplicity, rapidity, and high efficiency. Despite the efforts have made on Artemisia annua transient expression, achieving high-throughput gene functional characterization basing on a fast and easy-manipulated transient transformation system in $A$. annua remains challenging.

Results: The first pair of true leaves of A. annua is an ideal candidate for Agrobacterium injection. EHA105 was the optimal strain that can be used for the development of the transient expression system. The supplementation of Triton X-100 at a concentration of $0.005 \%$ greatly improved the transient expression frequency. According to the histochemical $\beta$-Glucuronidase (GUS) staining assay, high transient expression level of the reporter gene (GUS) maintained at least a week. Dual-luciferase (Dual-LUC) transient assays showed that the activity of cauliflower mosaic virus $35 S$ (CaMV35S) promoter and its derivates varied between A. annua and tobacco. In A. annua, the CaMV35S promoter had comparable activity with double CaMV35S promoter, while in tobacco, CaMV35S exhibited approximately 50\% activity of double CaMV35S promoter. Otherwise, despite the CaMV35S promoter and double CaMV35S promoter from GoldenBraid Kit 2.0 displayed high activity strength in tobacco, they demonstrated a very low activity in transiently expressed A. annua. The activity of UBQ10 promoter and endogenous UBQb promoter was investigated as well. Additionally, using our transient expression system, the transactivation of AaGSW1 and AaORA on AaCYP71AV1 promoter was confirmed. Dual-LUC assays demonstrated that AaHD8 activated the expression of two glandular secreting trichomes-specific lipid transfer protein genes AaLTP1 and AaLTP2, indicating that AaLTP1 and AaLTP2 might serve as downstream components of AaHD8-involved glandular trichome initiation and cuticle formation, as well as artemisinin secretion in A. annua.
\end{abstract}

\footnotetext{
*Correspondence: kxtang@sjtu.edu.cn

1 Joint International Research Laboratory of Metabolic

and Developmental Sciences, Key Laboratory of Urban Agriculture

(South) Ministry of Agriculture, Plant Biotechnology Research

Center, Fudan-SJTU-Nottingham Plant Biotechnology R\&D Center,

School of Agriculture and Biology, Shanghai Jiao Tong University,

Shanghai 200240, China

Full list of author information is available at the end of the article
}

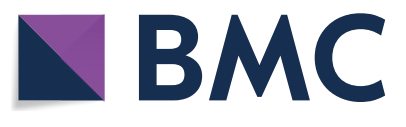

(c) The Author(s) 2021. Open Access This article is licensed under a Creative Commons Attribution 4.0 International License, which permits use, sharing, adaptation, distribution and reproduction in any medium or format, as long as you give appropriate credit to the original author(s) and the source, provide a link to the Creative Commons licence, and indicate if changes were made. The images or other third party material in this article are included in the article's Creative Commons licence, unless indicated otherwise in a credit line to the material. If material is not included in the article's Creative Commons licence and your intended use is not permitted by statutory regulation or exceeds the permitted use, you will need to obtain permission directly from the copyright holder. To view a copy of this licence, visit http://creativecommons.org/licenses/by/4.0/. The Creative Commons Public Domain Dedication waiver (http://creativeco mmons.org/publicdomain/zero/1.0/) applies to the data made available in this article, unless otherwise stated in a credit line to the data. 
Conclusions: A simple, rapid, good-reproducibility, high-efficiency and low-cost transient transformation system in A. annua was developed. Our method offered a new way for gene functional characterization studies such as gene subcellular localization, promoter activity and transcription activation assays in A. annua, avoiding the aberrant phenotypes resulting from gene expression in a heterologous system.

Keywords: Artemisia annua, Transient transformation, Transcription factor, Promoter activity, Transcription activation

\section{Background}

Agrobacterium tumefaciens has the ability to integrate transferred DNA (the T-DNA) into its host plant genome, and thus is a commonly used tool for plant genetic transformation $[1,2]$. While the stable genetic transformation endows transformed plants with hereditable new characteristics, transient plant transformation mediated by $A$. tumefaciens is widely applied for high-throughput gene function studies due to its simplicity, rapidity and high efficiency [2-4]. In comparison to stable transformation, introduced DNA segments are often expressed at much higher levels, albeit transiently, when introduced into plant cells via transformation [5]. Most of the widely used transient transformation assays involve introduction of Agrobacterium into plants using vacuum-aided infiltration technique or a disposable needless syringe $[6,7]$. Given the advantages of high efficiency transformation of tobacco, the leaf agro-infiltration method was firstly established in Nicotiana sylvestris and then adapted for fast gene functional characterization studies [8, 9]. Based on $N$. benthamiana system, researchers have developed varieties of transient expression assays such as protein subcellular localization, protein-protein interaction (Co-immunoprecipitation assay, Co-IP and bimolecular fluorescence complementation assay, BiFC), as well as protein-DNA interaction (dual-luciferase assay), to test gene function and regulation in plant cells in a very short time [10-13]. In addition to tobacco, agro-infiltration has proved effective in diverse plant species including Arabidopsis thaliana [7, 13, 14], Vitis vinifera [15], Theobroma cacao [16], Gossypium hirsutum [17], Malus domestica [18] and Caragana intermedia [19].

Artemisia annua, a widely distributed Chinese medicinal plant belonging to Asteraceae family, is the main and only natural source of artemisinin that is famous for its use as antimalarial drugs [20-22]. Recent years, our group have already identified and characterized a number of transcription factors (TFs) playing significant roles in artemisinin biosynthetic pathway and trichome initiation as well as their transcriptional regulatory networks, using $N$. benthamiana transient expression system [2228]. However, gene expression in a heterologous system may result in aberrant phenotypes [29] and N. benthamiana platforms are not appropriate for studies on speciesspecific metabolites. Moreover, multigene engineering may require the use of different promoters to avoid the gene silencing caused by the repeated use of the same promoter in the same construct [30]. Transient transformation is an effective approach for fast detection of promoter activity in different plant species and thus provide suitable promoters for plant multigene engineering. For A. annua transient transformation, Ma et al. introduced A. tumefaciens into leaves cut from 4-week-old aseptic seedlings using vacuum method [31], and our group carried out the transient expression study by transfecting protoplasts that were prepared from 2-week-old $A$. annua mesophyll cells [22]. However, neither method can be considered high throughput as one procedure requires specialized equipment, whereas the other involves complex protoplast isolation. An additional drawback of these two published methodologies is that gene expression can only be monitored for several days before excessive growth of the Agrobacterium interferes with the experiment. Given this, a high efficiency and easy manipulated transient expression system in $A$. апnиа especially in planta is needed to be developed.

In the present study, we developed an Agrobacteriummediated leaf transformation method by injecting the first pair of true leaves of 2-week-old $A$. annua seedlings using a $1 \mathrm{~mL}$ needless syringe. Specifically, we verified the applicability of our transient expression system on promoter activity detection and transcription activation assays. We compared the activity of various CaMV35S promoter and its derivates in tobacco and $A$. апnua. Results of our experiments showed that the activity strength of CaMV35S promoter and double CaMV35S promoter from GoldenBraid Kit 2.0 in A. annua was very low. The activity of UBQ10 promoter from Arabidopsis and an endogenous polyubiquitin promoter $\mathrm{UBQb}$ was also assessed. Moreover, we show that AaLTP1 and AaLTP2, which are involved in artemisinin accumulation and secretion in $A$. апnиa, are potentially regulated by AaHD8.

\section{Methods \\ Plant materials and growth conditions}

A. апnи $\mathrm{L}$. used for developing transient expression system in this study is a high-artemisinin cultivar, 'Huhao 1', which has been subjected to several years selection in Shanghai [32]. Seeds of A. annua and N. benthamiana 
were sown in $9 \mathrm{~cm}$ pots and grown in a greenhouse as previously described [33].

\section{Agrobacterium transformation}

The Agrobacterium strain LBA4404, GV3101 and EHA105 competent cells (Weidi Bio Tech, Shanghai, China) stored at -80 were thawed on ice and added 5 $\mu \mathrm{L}$ recombined plasmids, then kept in ice for $5 \mathrm{~min}$. Then the mixture was fast frozen in liquid nitrogen for $5 \mathrm{~min}$, followed by an incubation at $37{ }^{\circ} \mathrm{C}$ for $5 \mathrm{~min}$. After that, the mixture was kept in ice for $5 \mathrm{~min}$ and added $300 \mu \mathrm{L}$ fresh Luria Broth (LB) liquid medium. After a culture in shaker for $1 \mathrm{~h}$ at $28{ }^{\circ} \mathrm{C}, 200 \mathrm{rpm}, 100 \mu \mathrm{L}$ cells were plated on a $\mathrm{LB}$ agar plate containing rifampicin $(25 \mathrm{mg} / \mathrm{L})$ and kanamycin $(100 \mathrm{mg} / \mathrm{L})$, and then cultured for $2-3$ days in dark at $28{ }^{\circ} \mathrm{C}$.

\section{Agrobacterium culture and preparation of infiltration}

A single positive colony of Agrobacterium was inoculated in $1 \mathrm{~mL}$ LB liquid medium ( $25 \mathrm{mg} / \mathrm{L}$ rifampicin and $100 \mathrm{mg} / \mathrm{L}$ kanamycin) and cultured for $18-24 \mathrm{~h}$ in a shaker at $28{ }^{\circ} \mathrm{C}, 200 \mathrm{rpm}$. Then, $500 \mu \mathrm{L}$ Agrobacterium cells were transferred into $10 \mathrm{~mL}$ fresh $\mathrm{LB}$ liquid medium supplemented with above-mentioned antibiotics and cultured overnight at $28{ }^{\circ} \mathrm{C}, 200 \mathrm{rpm}$. An aliquot of $2 \mathrm{~mL}$ Agrobacterium cells were pelleted by centrifugation (4000 rpm, $5 \mathrm{~min}$ ) and re-suspended with $500 \mu \mathrm{L}$ Murashige and Skoog (MS) medium (3\% (w/v) sucrose, $\mathrm{pH}$ 5.7). The re-suspended cells were then diluted to $\mathrm{OD}_{600}=0.8$ with infiltration solution [above-mentioned MS medium, $200 \mu \mathrm{M}$ acetosyringone (AS), $10 \mathrm{mM}$ MES monohydrate ( $\mathrm{pH} 5.7)]$. After a resting of $3 \mathrm{~h}$, the Agrobacterium solution was mixed with Triton X-100 at a concentration of $0.005 \%$ and ready for infiltration.

\section{Infiltration of the $A$. annua leaves}

The first pair of true leaves of 2-week-old A. annua seedlings was transformed by injection of Agrobacterium strain cells harboring corresponding plasmids to the abaxial surface using a $1 \mathrm{~mL}$ disposable needleless syringe. After injection, the leaf-infiltrated $A$. annua seedlings were dried with paper, covered with a clear plastic lid to keep the humidity, and then moved in dark. After 24-h cultivation, the plants were transferred to greenhouse with a16-h light/8-h dark photoperiod at $23 \pm 2{ }^{\circ} \mathrm{C}$ for recovery growth. $12 \mathrm{~h}$ later, the cover was removed and then the plants were kept under normal growth conditions until sample harvest.

\section{Fluorescence microscopy}

The eGFP was ligated into $p E A Q-H T-D E S T 1$ (GenBank: GQ497235.1) to obtain the pEAQ-HT-DEST1-eGFP construct as Stephenson et al., described [34]. Different
Agrobacterium strains harboring the $p E A Q-H T-D E S T 1-$ eGFP plasmid, were infiltrated into $A$. annua leaves to monitor the transient expression. Pictures were captured at $4 \times$ and $10 \times$ objective with an OLYMPUS BX51 microscope (Tokyo, Japan) at $3 \mathrm{dpi}$ (days post injection). The primers were synthesized by Sangon (Shanghai, China), and all the primers used in this study are listed in Additional file 1: Table S1.

\section{Luciferase (LUC) assay}

For the construction of $p D G B 3 \alpha 1-35 S-L U C$-Tnos, GoldenBraid Kit 2.0 [30] was used to assemble DNA elements. CaMV35S promoter from $\mathrm{pHB}$ vector was amplified using the primers designed by GoldenBraid 4.0 (https:// gbcloning.upv.es) and ligated into the universal acceptor plasmid pUPD2. Next, pUPD2-35S, together with pLuciferase (GB0096) and pTnos (GB0037) (http://www. addgene.org/kits/orzaez-goldenbraid2/\#kit-contents) were assembled into pDGB3_alpha1 vector in one reaction. The detailed information for DNA parts assembly method can be found in our previous study [35]. The construct $p D G B 3 \alpha 1-35 S-L U C-T$ nos was then respectively introduced into Agrobacterium strain LBA4404, GV3101 and EHA105 cells and transiently transformed into $A$. annua leaves to evaluate the transient expression efficiency using LUC assay. Briefly, $1.5 \mathrm{~mL}$ Microcentrifuge tubes (NEST, Wuxi, China) containing two steel beads and $0.03 \mathrm{~g}$ fresh leaf each sample, accompanied with the steel adaptor, were frozen in liquid nitrogen for several seconds, and immediately placed into the tissuelyser. Then the tissue powder was obtained by fast bead beating for $60 \mathrm{~s}$ with $55 \mathrm{HZ}$. LUC activity was measured according to the manufacturer's instructions (Luciferase Reporter Gene Assay Kit, Yeasen, Shanghai, China). The primers were synthesized by Sangon (Shanghai, China), and all the primers used in this study are listed in Additional file 1: Table S1.

\section{Western blot analysis}

The A. аnnua leaves transiently transformed by Agrobacterium strain EHA105 carrying eGFP construct were subjected to protein extraction and Western blot analysis. Two leaves were ground into powder using a tissuelyser as mentioned above. The fine powder was then resuspend using $200 \mu \mathrm{L}$ Lysis buffer [150 mM Tris-HCl (pH 8.0), 25\% Glycerol, 3\% PVP, 2\% NaCl, 1\% Triton X-100, and protease inhibitors including $100 \mu \mathrm{M}$ Pefabloc (SigmaAldrich, USA), $100 \mu \mathrm{M}$ cocktail (Roche, Switzerland), and $50 \mu \mathrm{M}$ MG132 (Calbiochem, USA)] and incubated on ice for $1 \mathrm{~h}$. After centrifugation at 14,000 rpm for $10 \mathrm{~min}$, the supernatant was detected using Western blot analysis as previously described [22]. 


\section{Histochemical $\beta$-glucuronidase (GUS) staining}

The CaMV35S promoter isolated from $\mathrm{pHB}$ vector was cloned into pCAMBIA1391Z vector to drive the expression of GUS using ClonExpress ${ }^{\circledR}$ II One Step Cloning Kit (Vazyme, Nanjing, China). Then the Agrobacterium strain EHA105 harboring p1391Z-35S-GUS plasmid was injected into the leaves of $A$. annua seedlings. The infiltrated leaves were collected after 2-7 days post injection (dpi) and used for histochemical GUS staining assay as previously described $[22,36]$. The primers were synthesized by Sangon (Shanghai, China), and all the primers used in this study are listed in Additional file 1: Table S1.

\section{Dual-LUC transient assay}

The CaMV35S promoter and double CaMV35S promoter from $\mathrm{pHB}$ vector as well as CaMV35S promoter and double CaMV35S promoter from GoldenBraid Kit 2.0, were cloned and ligated into pGreenII0800-LUC vector using ClonExpress ${ }^{\circledR}$ II One Step Cloning Kit (Vazyme, Nanjing, China) to drive the expression of $L U C$ gene, while the Renilla LUC (REN) gene under the control of a CaMV35S promoter was used as an internal control [37]. In addition, the promoters of $A$. annua polyubiquitin$b$ and Arabidopsis polyubiquitin 10 from GoldenBraid Kit 2.0, were also cloned and ligated into pGreenII0800LUC vector to investigate their activity in both tobacco and $A$. annua transient expression systems. The promoter sequences can be found in Additional file 1. Two days after injection with Agrobacterium strain EHA105 cells harboring the indicated vectors and helper plasmid pSoup 19, the first pair of leaves of $A$. annua seedlings was respectively harvested and ground into fine powder in liquid nitrogen for firefly LUC and REN activities analysis using the Dual-Luciferase ${ }^{\circledR}$ Reporter Assay System (Promega, USA). The relative LUC/REN ratios representing the activity of the promoters were used to evaluate the transient expression system. The primers were synthesized by Sangon (Shanghai, China) and all the primers used in this study are listed in Additional file 1: Table S1.

For the transcriptional activation activity experiments, the full-length coding sequences of AaGSW1, AaORA and $A a H D 8$ were inserted into the pHB-YFP (yellow fluorescent protein) vector as effectors, while the promoter sequences of AaCYP71AVA, AaHD1, AaLTP1 and AaLTP2 were fused to pGreenII0800-LUC vector act as reporters. The detailed information for the constructs can be found in our previous work [23, 25, 26]. For each experiment, four independent plants were, respectively harvested and measured the relative LUC activities. Three independent experiments were performed.

\section{Results}

The first pair of true leaves of $A$. annua is an ideal candidate for Agrobacterium injection

Normally, the leaves of $A$. апnиa are odd-pinnately compound with deeply indented margins [38]. Here we found that the first pair of true leaves of $A$. annua exhibits a single and lobed leaf morphology (Fig. 1), which is a good candidate for Agrobacterium injection.

\section{Development of the transient transformation method in $A$. annua leaves}

To determine whether the first pair of true leaves is appropriate for transient expression, three wildly used Agrobacterium strains including LBA4404, GV3101 and EHA105 harboring the pEAQ-HT-DEST1-eGFP construct were injected into the abaxial surface of 2-week-old $A$. annua leaves. After injection, the plants were moved in dark at $25{ }^{\circ} \mathrm{C}$ for $24 \mathrm{~h}$. However, leaf wilt symptoms were induced within 1 day post injection (dpi) (Additional file 1: Figure S1). To address this issue, we dried off the injected leaves with paper towel gently, and covered a clear plastic lid to keep the humidity. This greatly improved the recovery growth of

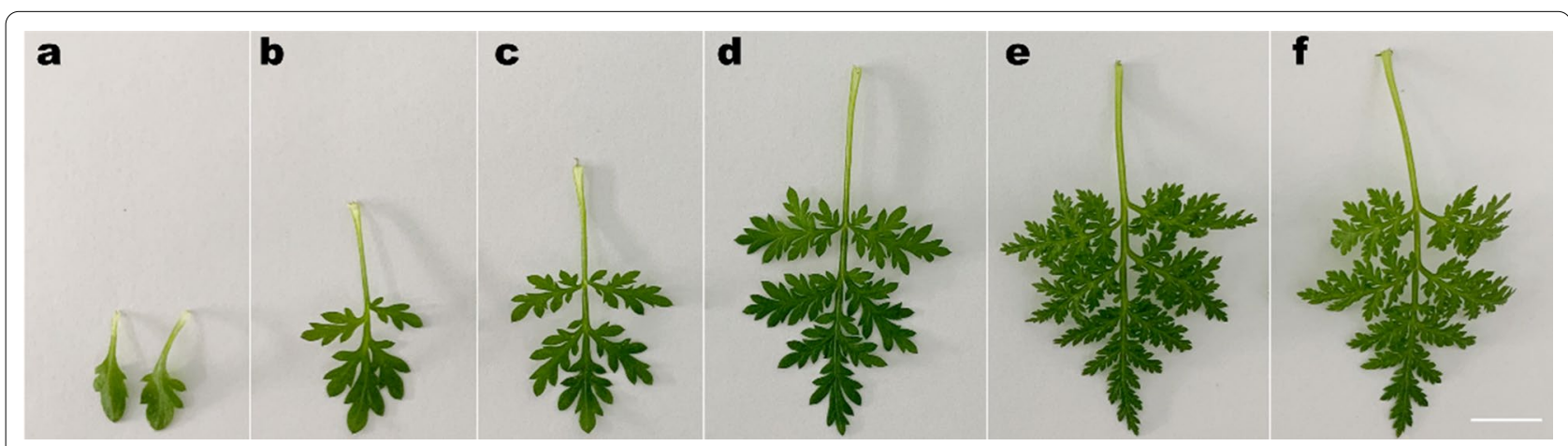

Fig. 1 Leaf morphology of 1-month-old A. annua. The first pair of true leaves (a) and leaf 3-7 (b-f). Bar $=1 \mathrm{~cm}$ 
infiltrated-A. аппиа seedlings. Therefore, the following transient transformation of $A$. апnиa was performed according to the workflow depicted in Fig. 2.

According to the fluorescence microscopy, EHA105mediated transient transformation of eGFP in $A$. annua showed strongest GFP fluorescent signals, followed by GV3101, while no GFP fluorescent signals were observed in the $A$. annua leaves transiently transformed with LBA4404 (Fig. 3a). Consistently, A. annua leaves transiently expressed LUC mediated by EHA105 showed highest LUC activity (Fig. $3 \mathrm{~b}$ ). In addition, the use of surfactants such as Silwet L-77, Tween 20 and Triton X-100 at a concentration of $0.005 \%$ drastically improved the transient expression of $L U C$ gene, while the addition of Triton X-100 in the infiltration solution resulted in the strongest LUC activity (Fig. 3c). In accordance with the LUC assay, enhanced fluorescence intensity was observed at $3 \mathrm{dpi}$ with the addition of Triton X-100 in the infiltration solution (Fig. 3d). The expression of GFP was further detected using Western blot (Fig. 3e).

To further test the transient expression system, leaves injected with Agrobacterium EHA105 strain harboring the p1391Z-35S-GUS were, respectively collected at 2, 3, 4, 5, 6 and 7 dpi for GUS staining analysis. GUS staining results showed that, the GUS gene expression can be detected at $2 \mathrm{dpi}$ and maintained a high level until the $7 \mathrm{dpi}$ (Fig. 4).

\section{Using the agro-infiltration method to test promoter activity}

To detect the activity of CaMV35S promoter and its derivates, as well as polyubiquitin promoters in leaves of tobacco and $A$. annua, we measured the firefly LUC and REN activities using Dual-LUC assay (Fig. 5a). As is shown in Fig. 5b, although, double CaMV35S promoter was approximately two-fold more active than CaMV35S promoter in tobacco, the activity of double CaMV35S promoter in A. annua was similar to that of CaMV35S promoter. Moreover, unlike in tobacco, the CaMV35S promoter (g35S) and double CaMV35S promoter $(\mathrm{g} 2 \times 35 \mathrm{~S})$ from GoldenBraid Kit 2.0 displayed strong activity, a very low activity was observed in $A$. annua. In addition to CaMV35S promoters, Arabidopsis ubiquitin promoter (UBQ10) was found suitable for plant transformation studies [39, 40]. Therefore, the characterization of endogenous ubiquitin promoter would be beneficial for future studies of $A$. annua. Based on the RNA-seq data [41], we observed that the expression of Aannua02727S332000, which is homologous to Arabidopsis UBQ10, is lower than Aannua01692S241190 (polyubiquitin- $b$ ) in all the tested organs/tissues of $A$. annua (Additional file 1: Figure S2). Then, the promoter of polyubiquitin-b (UBQb), together with Arabidopsis UBQ10 from GoldenBraid Kit 2.0 were cloned for activity analysis. In tobacco, UBQ10 exhibited higher promoter activity than $\mathrm{UBQb}$, and is comparable with g35S, while in

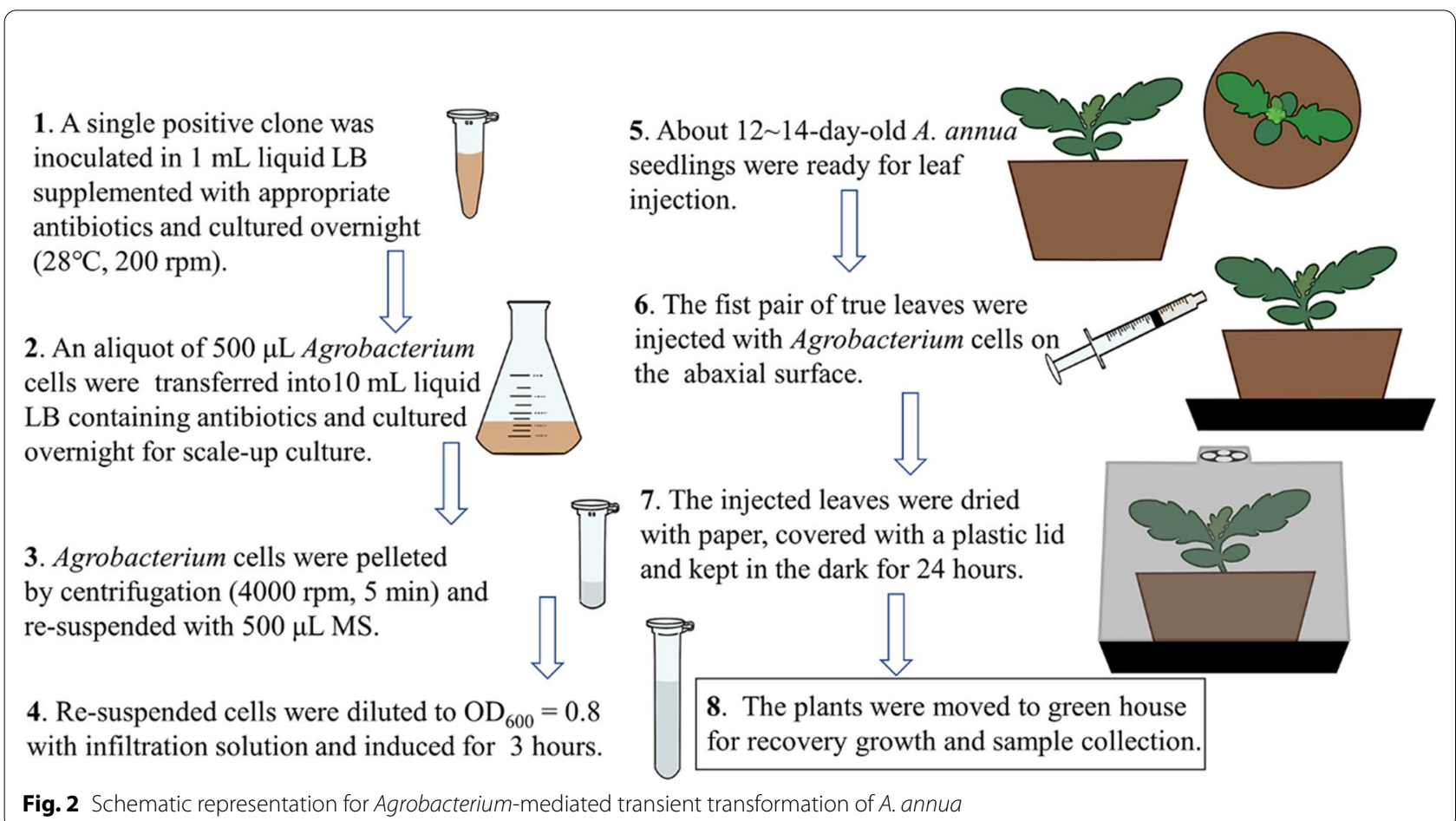



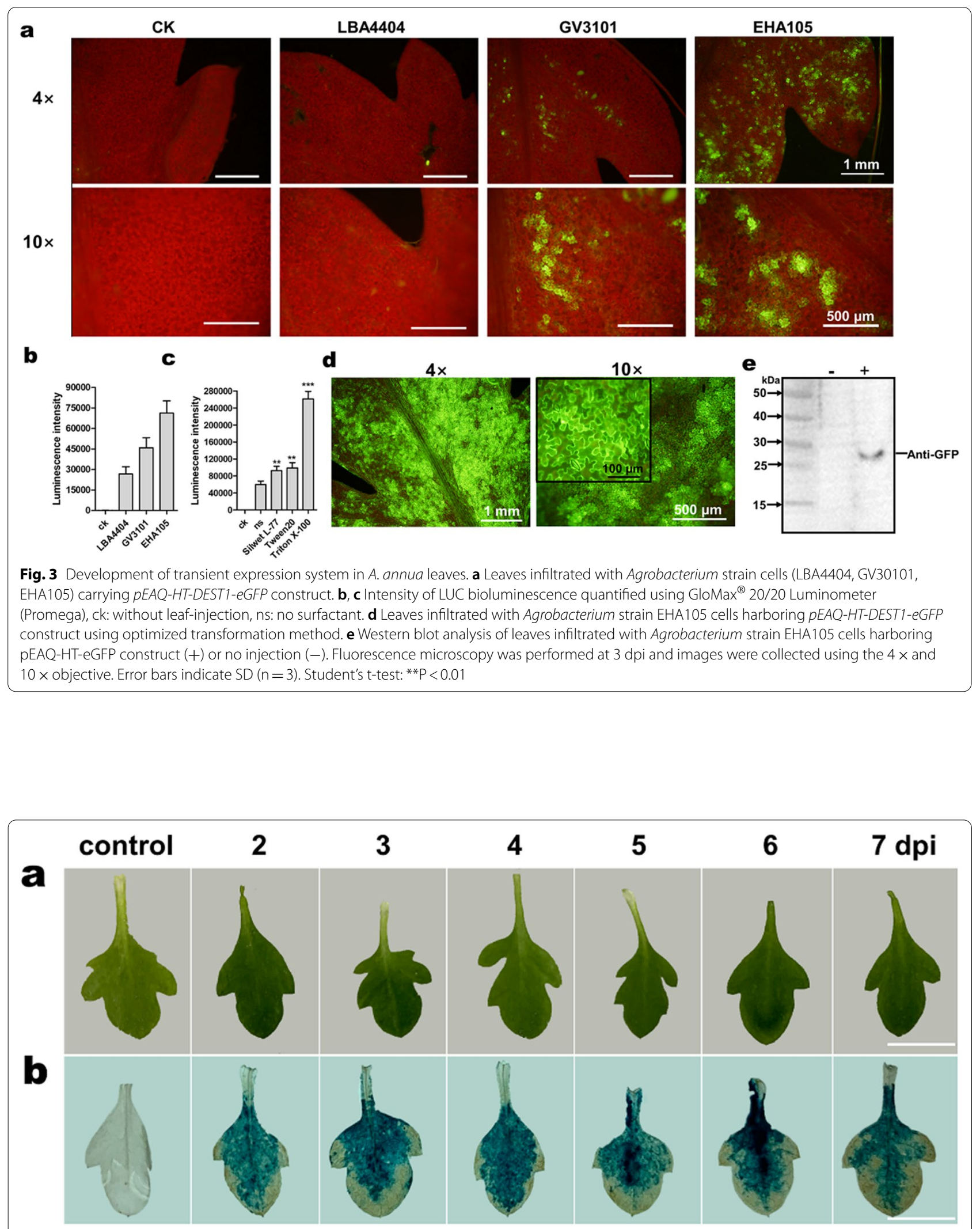

Fig. 4 GUS staining analysis of A. annua leaves transiently expressing p1391Z-35S-GUS constructs at different days post injection (dpi). a Phenotype of $A$. annua leaves at 2-7 dpi and ck (without leaf-injection). $\mathbf{b}$ GUS staining analysis $A$. annua leaves at 2-7 dpi and control. Bars $=0.5 \mathrm{~cm}$ 


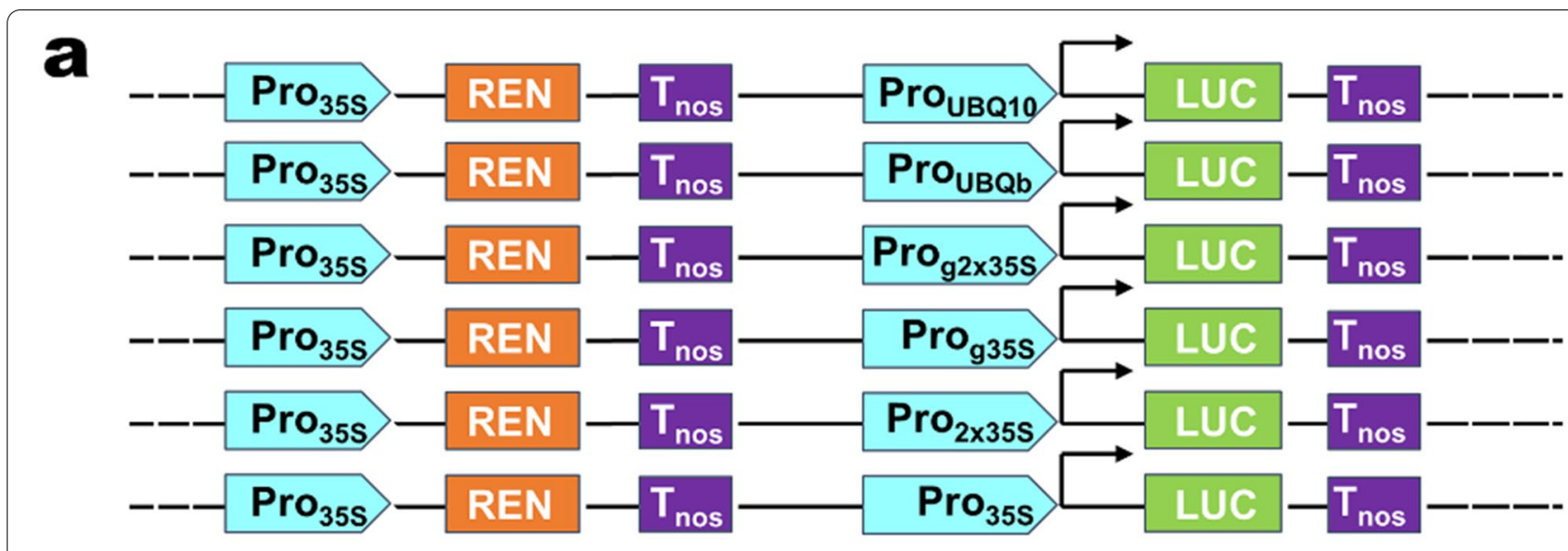

b

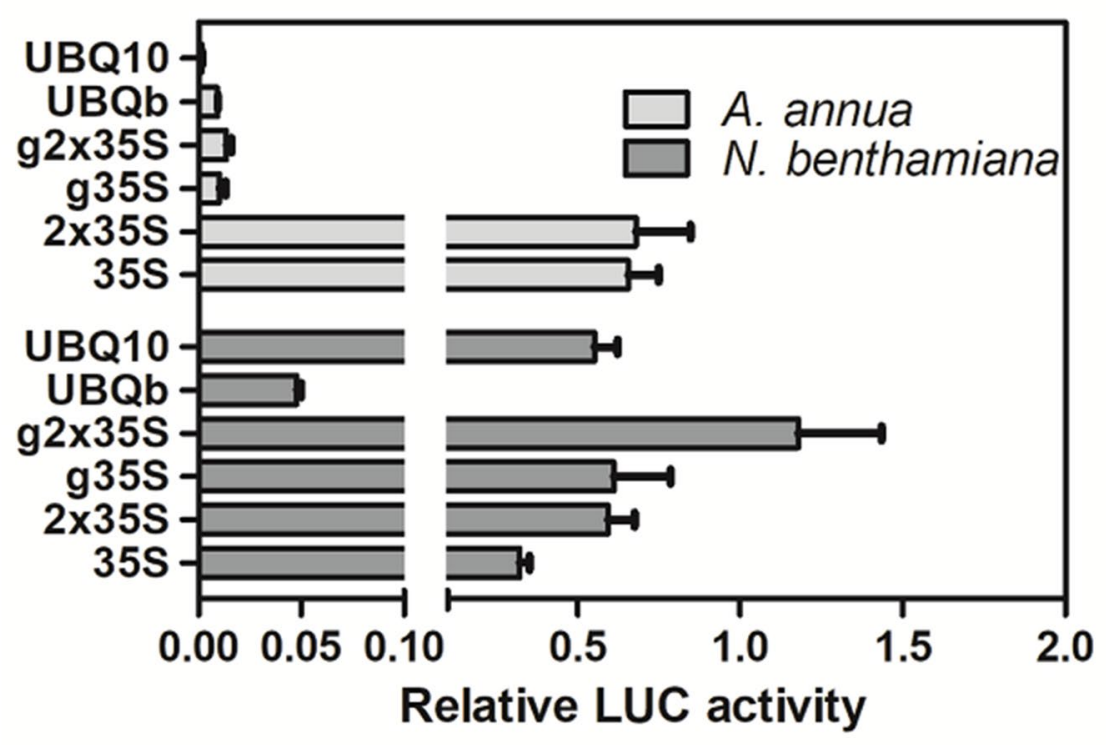

Fig. 5 Promoter activity analysis of CaMV35S and polyubiquitin promoters in A. annua and tobacco using Dual-LUC assay. a Schematic diagram of the Dual-LUC constructs. b Relative LUC activity of CaMV35S and polyubiquitin promoters in A. annua and tobacco. UBQ10, A. thaliana polyubiquitin 10 (AtUBQ10) promoter, UBQb, A. annua polyubiquitin-b (AaUBQb) promoter, g2 $\times 35 \mathrm{~S}$ and g35S represent double and single CaMV35S promoter from GoldenBraid Kit 2.0, $35 \mathrm{~S}$ and $2 \times 355$ represent the corresponding promoters from $\mathrm{pHB}$ vector

A. annua the activity of UBQ10 is lower than UBQb (Fig. 5b).

\section{Using the agro-infiltration method to test transcriptional activation activity}

We have previously showed AaGSW1 and AaORA regulate the artemisinin biosynthesis by directly binding to the promoter of $C Y P 71 A V 1$ and activating its expression $[23,26]$. To test the applicability of our transient expression system, Dual-LUC assays were conducted to confirm the interaction of AaGSW1 and AaORA and $A a C Y P 71 A V 1$ promoter. As expected, both AaGSW1 and
AaORA significantly activated the expression of $\mathrm{AaCY}$ P71AV1 promoter (Fig. 6a).

Next, we employed this transient transformation method to investigate a new transcriptional regulation relationship in artemisinin biosynthesis and accumulation pathways in A. annua. AaHD8, a homeodomain-leucine zipper (HD-ZIP) IV transcription factor, has been previously reported to boost the artemisinin production by activating the expression of $A a H D 1$, which played important roles on promoting glandular trichome initiation [25]. The regulatory network of AaHD8 enhancing the artemisinin accumulation by increasing trichome 


\section{a}

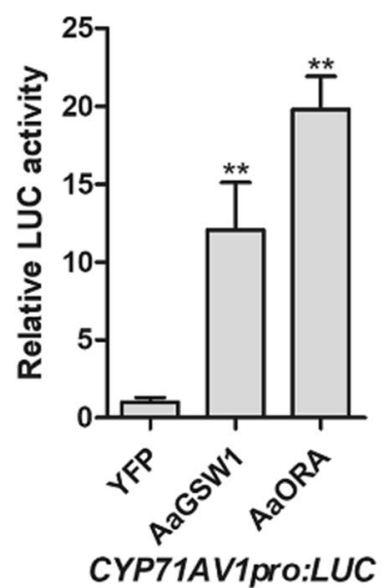

b

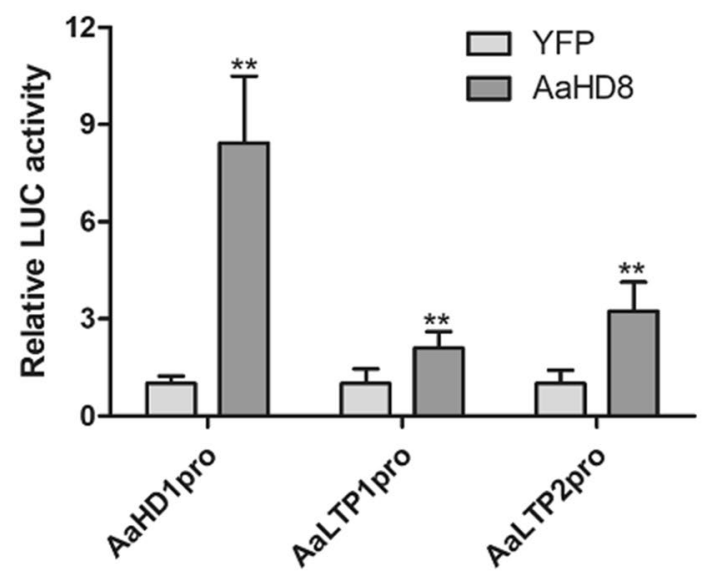

Fig. 6 Dual-LUC assay in A. annua cells. a Activation of CYP71AV1 gene promoter by AaGSW1 and AaORA. b Activation of AaHD1, AaLTP1 and AaLTP2 gene promoters by AaHD8. The pHB-YFP was used as a negative control. The promoters of AaCYP71AVA, AaHD1, AaLTP1 and AaLTP2 were fused to drive the expression of Firefly luciferase (LUC) gene while the Renilla luciferase (REN) gene under the control of a CaMV35S promoter was used as an internal control, and the LUC/REN ratio of YFP was set as 1. Error bars indicate SD $(n=3)$. Student's t-test: ${ }^{* *}, \mathrm{P}<0.01$

density has been sufficiently elucidated. However, the underlying mechanism involved in artemisinin secretion modulated by AaHD8 remains unclear. According to the comparison between $A a H D 8$-silenced lines and WT plants transcriptome data, we found two lipid transfer protein genes AaLTP1 and AaLTP2, which are specifically expressed in glandular secreting trichome (GST), were significantly downregulated by 114 and 86-fold, respectively [25]. Furthermore, according to the RNA-seq data for seed, root, leaf, bud and trichome [41], AaLTP1 and AaLTP2 showed similar expression pattern with $A a H D 8$, as well as the four structural artemisinin biosynthesis genes $A D S, C Y P 71 A V 1, D B R 2$ and $A L D H 1$ in the examined organs/tissues (Additional file 1: Figure S3). Meanwhile, in the AaLTP1-overexpressed lines, pronounced enhancement of artemisinin production was observed (unpublished data). Here, we carried out DualLUC assays in A. annua leaves to assess the capacity of AaHD8 to transactivate the AaLTP promoters. As we can see in Fig. 6b, AaHD8 significantly activated the expression of $A a L T P 1$ and $A a L T P 2$, as well as AaHD1 promoters in A. annua leaves.

\section{Discussion}

Transgenic plants are widely used to produce valuable metabolites or functional proteins $[42,43]$. In addition to the application on production, transgenic technology is a very important approach to introduce useful traits into plants [44-46] as well as characterize the function and regulation of novel genes $[47,48]$. However, for many plant species, stable transformation is time-consuming and unsuitable for large-scale analyses [29]. Agrobacterium-mediated transient transformation is capable of expressing the target genes transiently with a high level, and hence is facile and versatile for the high-throughput gene functional characterization in plants, such as promoter activity, transcriptional regulation, protein subcellular localization and protein-protein interaction [19]. Researchers have well established the leaf agro-infiltration transient expression system in $N$. benthamiana, which is a commonly used platform for transient gene expression analysis [49]. Despite the advantages offered by tobacco transient expression system, a homologous gene transfer system is significantly needed for each plant species to avoid the undesirable affects caused by heterologous gene expression $[50,51]$.

A. annua is generally recognized as a safe plant source for the extraction and purification of artemisinin, which has important roles in combating malaria [52, 53]. Moreover, the recently published genome sequence of $A$. annua [41] was believed to accelerate the research on gene function and promoter characterization. Previous studies have proved that promoter activity varied in different plant species. For instance, the most frequently used promoter CaMV35S could constitutively drive high level of gene expression in dicots, however less effective in monocots, such as rice and corn [54]. Besides, GUS activity in transgenic chrysanthemums using the CaMV35S promoter was low [55]. Similar results were also observed in chickpea [56]. Notably, 
along with the rapid development of DNA assembly technologies, multigene transformation which has the ability to introduce more complex and ambitious phenotypes into transgenic plants, is becoming more and more frequently-used in plant biotechnology [57]. However, repetitious promoter use in one construct may cause homology dependent gene silencing [58]. Therefore, it is necessary to seek more available promoters with desired activity strength.

Detecting the promoter activity using transient expression system has been well studied in many plant species [11, 14, 37, 59-61]. For A. annua, due to its odd-pinnately compound leaves with deeply indented margins, it is not appropriate for Agrobacterium injection (Fig. 1). $\mathrm{Ma}$ et al. performed the transient transformation by introducing $A$. tumefaciens into the leaves cut from 4-week-old aseptic seedlings using a vacuum pump [31], whereas our previous transient expression assays relied on protoplasts which were prepared from 2-week-old A. апnиа mesophyll cells as recipient cells [22]. Here, we developed a time-saving and easy-manipulated transient transformation method without the employ of additional equipment or isolation of mesophyll protoplasts. We found that the first pair of true leaves of $A$. annua was the most suitable material for Agrobacterium injection, which could also minimize the time required to conduct transient transformation assay. However, leaf necrosis was observed when using conventional transient transformation method (Additional file 1: Fig. S1). To avoid the leaf necrosis resulted from Agrobacterium injection, we used a paper towel to soak up the residual Agrobacterium fluid and kept the seedlings in a relative high humidity (Fig. 2), which was very helpful for the recovery growth of injected $A$. annua leaves. Among the three Agrobacterium strains chosen for transient transformation, EHA105 was the optimal strain that can be used for the development of the transient expression system (Fig. 3a, b). Nevertheless, GFP fluorescence was merely observed in occasional A. annua cells (Fig. 3a). Given that the presence of surfactants greatly improved transient transformation efficiency, we explored the use of Silwet L-77, Tween 20 and Triton X-100 which were helpful for bacteria to enter the intercellular space [13, 17, 62]. LUC assay showed that all the three surfactants were able to improve the efficiency of transient transformation in A. annua (Fig. 3c). Supplementation of Triton X-100 elevated the transient expression most markedly, which is similar to the results observed in transiently transformed Arabidopsis [62]. GUS staining results showed the reporter gene (GUS) continuously expressed and maintained its expression at least a week (Fig. 4). Moreover, our method can be used for promoter activity detection and transcriptional activation assays.
CaMV35S promoter and its derivates are constitutively expressed promoters widely used in plant biotechnology [63]. Intriguingly, we found CaMV35S promoter was effective as double CaMV35S promoter A. annua, whereas the activity of CaMV35S promoter was about $50 \%$ of double CaMV35S promoter in tobacco. Additionally, the CaMV35S promoter (g35S) and double CaMV35S promoter $(\mathrm{g} 2 \times 35 \mathrm{~S})$ from the GoldenBraid Kit 2.0 could drive higher level of heterologous gene expression in tobacco plants, than that of CaMV35S promoter and double CaMV35S promoter from $\mathrm{pHB}$ vector. However, the luciferase gene expression under the control of g35S and $\mathrm{g} 2 \times 35 \mathrm{~S}$ promoters in A. annua was very low (Fig. 5). Similarly, despite the strong activity of Arabidopsis UBQ10 promoter exhibited in tobacco, an extremely low activity was observed in A. апnua. Furthermore, in $A$. annua transient expression system, the endogenous polyubiquitin promoter $\mathrm{UBQb}$ showed higher activity than Arabidopsis UBQ10 promoter. These results indicated that promoter activity was different in various genetic background. Thereby, the activity of promoters in a plant species needs to be investigated prior to being applied for further study.

We also report here that this transient transformation method can be used to test transcriptional activation activity. As is shown in Fig. 6a, AaGSW1 and AaORA positively regulate the expression of $A a C Y P 71 A V 1$, which is in accordance with our previous studies. Overexpression of AaLTP3 and AaLTP4 have proved to result in the increase of sesquiterpene lactones production including arteannuin B, artemisinin, dihydroartemisinic acid and artemisinic acid [64]. Nevertheless, AaLTP3 is specifically expressed in non-GSTs, while AaLTP4 is expressed in both non-GSTs and GSTs, while artemisinin is mainly synthesized and accumulated in GSTs. Recently, two GSTs-specific AaLTPs AaLTP1 and AaLTP2 were functionally characterized (unpublished data). As expected, AaLTP1-overexpressed lines exhibited higher artemisinin accumulation as compared with the WT plants. Since overexpression of AaHD8 increased the expression of AaLTP1 and AaLTP2 drastically, we speculated that AaHD8 appeared to be transcription activator of AaLTP1 and AaLTP2 and therefore regulated glandular trichome initiation and sesquiterpene lactone secretion, resulting in elevated artemisinin accumulation. Consistent with this interpretation, based on the Dual-LUC assay results, AaHD8 significantly boosted the expression of AaLTP1 and AaLTP2 promoters (Fig. 6b), indicating that AaHD8 was a positive regulator of AaLTP1 and AaLTP2. However, clarification of the regulatory relationship among them still needs further investigation. It should be mentioned that the recent release of genome information about $A$. annua by our laboratory provides a powerful 
platform for A. annua genetics study and breeding, and we strongly believe that this method will prove highly useful for future research performed on A. annua.

\section{Conclusion}

In summary, we developed a simple, rapid, high-efficiency and easy-manipulated transient expression system in A. апnиа. Our method can be used for gene functional characterization studies such as promoter activity detection and transcriptional activation assays in A. annua, avoiding the aberrant results caused by gene expression in a heterologous system. Moreover, our transient expression system provides a new way for fast characterization of putative promoters with desirable activity in A. annua, which is necessary to overcome gene silencing resulting from the use of multiple copies of the same promoter in multigene engineering.

\section{Supplementary Information}

The online version contains supplementary material available at https://doi. org/10.1186/s13007-021-00807-5.

Additional file 1: Figure S1 Necrosis was observed in leaves infiltrated with Agrobacterium cells harboring PEAQ-HT-DEST1-eGFP construct at 24 hours post injection. Figure $\mathbf{S} \mathbf{2}$ Heatmap of the expression levels of $A$. annua polyubiquitin genes in different organs/tissues. Figure $\mathbf{S 3}$ Heatmap of the expression levels of A. annua LTP2, LTP1 and HD8, as well as four structural artemisinin biosynthesis genes in different organs/tissues. Table S1 Primers used in this article.

\section{Acknowledgements}

We would like to thank Dr. Qian Shen for assistance in troubleshooting the transient transformation protocol and promoter activity measurement. We acknowledge Dr. Zhenhua Liu for providing pEAQ-HT-DEST1 plasmid.

\section{Authors' contributions}

$Y P L, X Q F, L L$ and $K X T$ conceived and designed the experiments. YPL, TTC, $W W, X Q F, X Y, Z K Y W$, and SK performed the experiments. YPL, $H L, L H X, W Q$, YJZ, CW, BWP and XHY analyzed the data. ZKYW helped with the schematic drawing. YPL drafted the manuscript. All authors read and approved the final manuscript.

\section{Funding}

This work was supported by National Key R\&D Program of China (2018YFA0900600), the Bill \& Melinda Gates Foundation (OPP1199872), the National Natural Science Foundation of China (31770327), SJTU Trans-med Awards Research (20190104) and SJTU Global Strategic Partnership Fund (2020 SJTU-CORNELL).

\section{Availability of data and materials}

All data generated or analyzed during this study are included in this published article.

\section{Declarations}

Ethics approval and consent to participate

Not applicable.

\section{Consent for publication}

All authors agreed to publish this manuscript.

\section{Competing interests}

The authors declare that they have no competing interests.

\section{Author details}

${ }^{1}$ Joint International Research Laboratory of Metabolic and Developmental Sciences, Key Laboratory of Urban Agriculture (South) Ministry of Agriculture, Plant Biotechnology Research Center, Fudan-SJTU-Nottingham Plant Biotechnology R\&D Center, School of Agriculture and Biology, Shanghai Jiao Tong University, Shanghai 200240, China. ${ }^{2}$ Center for Plant Biology, School of Life Sciences, Tsinghua University, Beijing 100084, China.

Received: 5 July 2021 Accepted: 5 October 2021

Published online: 16 October 2021

\section{References}

1. Chilton MD, Drummond MH, Merio DJ, Sciaky D, Montoya AL, Gordon MP, Nester EW. Stable incorporation of plasmid DNA into higher plant cells: the molecular basis of crown gall tumorigenesis. Cell. 1977;11(2):263-71.

2. Gelvin SB. Agricultural biotechnology: gene exchange by design. Nature. 2005:433(7026):583-4.

3. Yang Y, Li R, Qi M. In vivo analysis of plant promoters and transcription factors by agroinfiltration of tobacco leaves. Plant J. 2000;22(6):543-51.

4. Krenek P, Samajova O, Luptovciak I, Doskocilova A, Komis G, Samaj J. Transient plant transformation mediated by Agrobacterium tumefaciens: principles, methods and applications. Biotechnol Adv. 2015;33(6 Pt 2):1024-42.

5. Janssen BJ, Gardner RC. Localized transient expression of GUS in leaf discs following cocultivation with Agrobacterium. Plant Mol Biol. 1990;14(1):61-72.

6. Rossi L, Escudero J, Hohn B, Tinland B. Efficient and sensitive assay for T-DNA-dependent transient gene expression. Plant Mol Biol Report. 1993;11(3):220-9.

7. Wroblewski T, Tomczak A, Michelmore R. Optimization of Agrobacteriummediated transient assays of gene expression in lettuce, tomato and Arabidopsis. Plant Biotechnol J. 2005;3(2):259-73.

8. Tang X, Frederick RD, Zhou J, Halterman DA, Jia Y, Martin GB. Initiation of plant disease resistance by physical interaction of AvrPto and Pto Kinase. Science. 1996;274(5295):2060-3.

9. Schöb H, Kunz C, Meins F Jr. Silencing of transgenes introduced into leaves by agroinfiltration: a simple, rapid method for investigating sequence requirements for gene silencing. Mol Gen Genet. 1997;256(5):581-5.

10. Sparkes IA, Runions J, Kearns A, Hawes C. Rapid, transient expression of fluorescent fusion proteins in tobacco plants and generation of stably transformed plants. Nat Protoc. 2006;1(4):2019-25.

11. Chen $H$, Zou $Y$, Shang $Y$, Lin $H$, Wang $Y$, Cai R, Tang $X$, Zhou JM. Firefly luciferase complementation imaging assay for protein-protein interactions in plants. Plant Physiol. 2008;146(2):368-76.

12. Marion J, Bach L, Bellec Y, Meyer C, Gissot L, Faure JD. Systematic analysis of protein subcellular localization and interaction using highthroughput transient transformation of Arabidopsis seedlings. Plant J. 2008;56(1):169-79.

13. Zhang Y, Chen M, Siemiatkowska B, Toleco MR, Jing Y, Strotmann V, Zhang J, Stahl Y, Fernie AR. A highly efficient Agrobacterium-mediated method for transient gene expression and functional studies in multiple plant species. Plant Commun. 2020;1:100028.

14. Wu HY, Liu KH, Wang YC, Wu JF, Chiu WL, Chen CY, Wu SH, Sheen J, Lai EM. AGROBEST: an efficient Agrobacterium-mediated transient expression method for versatile gene function analyses in Arabidopsis seedlings. Plant Methods. 2014;10:19.

15. Liu YP, Peremyslov W, Medina V, Dolja VV. Tandem leader proteases of Grapevine leafroll-associated virus-2: host-specific functions in the infection cycle. Virology. 2009;383(2):291-9.

16. Fister AS, Shi Z, Zhang Y, Helliwell EE, Maximova SN, Guiltinan MJ. Protocol: transient expression system for functional genomics in the tropical tree Theobroma cacao L. Plant Methods. 2016;12:19. 
17. Li H, Li K, Guo Y, Guo J, Miao K, Botella JR, Song CP, Miao Y. A transient transformation system for gene characterization in upland cotton (Gossypium hirsutum). Plant Methods. 2018;14:50.

18. An JP, Wang XF, Li YY, Song LQ, Zhao LL, You CX, Hao YJ. EIN3-LIKE1, MYB1, and ETHYLENE RESPONSE FACTOR3 act in a regulatory loop that synergistically modulates ethylene biosynthesis and anthocyanin accumulation. Plant Physiol. 2018;178(2):808-23.

19. Liu K, Yang Q, Yang T, Wu Y, Wang G, Yang F, Wang R, Lin X, Li G. Development of Agrobacterium-mediated transient expression system in Caragana intermedia and characterization of CiDREB1C in stress response. BMC Plant Biol. 2019;19(1):237.

20. White NJ. Qinghaosu (artemisinin): the price of success. Science. 2008;320(5874):330-4.

21. Fu X, Shi $P$, He Q, Shen $Q$, Tang Y, Pan Q, Ma Y, Yan T, Chen M, Hao $X$, et al. AaPDR3, a PDR transporter 3, is involved in sesquiterpene $\beta$-Caryophyllene transport in Artemisia annua. Front Plant Sci. 2017;8:723.

22. Ma YN, Xu DB, Li L, Zhang F, Fu XQ, Shen Q, Lyu XY, Wu ZK, Pan QF, Shi $P$, et al. Jasmonate promotes artemisinin biosynthesis by activating the TCP14-ORA complex in Artemisia annua. Sci Adv. 2018;4(11):eaas9357.

23. Lu X, Zhang L, Zhang F, Jiang W, Shen Q, Zhang L, Lv Z, Wang G, Tang K. AaORA, a trichome-specific AP2/ERF transcription factor of Artemisia annua, is a positive regulator in the artemisinin biosynthetic pathway and in disease resistance to Botrytis cinerea. New Phytol. 2013;198(4):1191-202.

24. Yan T, Chen M, Shen Q, Li L, Fu X, Pan Q, Tang Y, Shi P, Lv Z, Jiang W, et al. HOMEODOMAIN PROTEIN 1 is required for jasmonate-mediated glandular trichome initiation in Artemisia annua. New Phytol. 2017;213(3):1145-55.

25. Yan T, Li L, Xie L, Chen M, Shen Q, Pan Q, Fu X, Shi P, Tang Y, Huang H, et al. A novel HD-ZIP IV/MIXTA complex promotes glandular trichome initiation and cuticle development in Artemisia annua. New Phytol. 2018;218(2):567-78

26. Chen M, Yan T, Shen Q, Lu X, Pan Q, Huang Y, Tang Y, Fu X, Liu M, Jiang W, et al. Glandular trichome-specific WRKY 1 promotes artemisinin biosynthesis in Artemisia annua. New Phytol. 2017:214(1):304-16.

27. Shi P, Fu X, Shen Q, Liu M, Pan Q, Tang Y, Jiang W, Lv Z, Yan T, Ma Y, et al. The roles of AaMIXTA1 in regulating the initiation of glandular trichomes and cuticle biosynthesis in Artemisia annua. New Phytol. 2018;217(1):261-76.

28. Hao X, Zhong Y, Hans-Wilhelm Witzmann NT, Fu X, Yan T, Shen Q, Chen M, Ma Y, Zhao J, Osbourn A, et al. Light-induced artemisinin biosynthesis is regulated by the bZIP transcription factor AaHY5 in Artemisia annua. Plant Cell Physiol. 2019;60(8):1747-60.

29. Jelly NS, Valat L, Walter B, Maillot P. Transient expression assays in grapevine: a step towards genetic improvement. Plant Biotechnol J. 2014;12(9):1231-45.

30. Sarrion-Perdigones A, Vazquez-Vilar M, Palací J, Castelijns B, Forment J, Ziarsolo P, Blanca J, Granell A, Orzaez D. GoldenBraid 2.0: a comprehensive DNA assembly framework for plant synthetic biology. Plant Physiol. 2013;162(3):1618-31.

31. Ma D, Pu G, Lei C, Ma L, Wang H, Guo Y, Chen J, Du Z, Wang H, Li G, et al. Isolation and characterization of AaWRKY1, an Artemisia annua transcription factor that regulates the amorpha-4,11-diene synthase gene, a key gene of artemisinin biosynthesis. Plant Cell Physiol. 2009;50(12):2146-61.

32. Shen Q, Lu X, Yan T, Fu X, Lv Z, Zhang F, Pan Q, Wang G, Sun X, Tang K. The jasmonate-responsive AaMYC2 transcription factor positively regulates artemisinin biosynthesis in Artemisia annua. New Phytol. 2016:210(4):1269-81.

33. Li Y, Qin W, Fu X, Zhang Y, Hassani D, Kayani SI, Xie L, Liu H, Chen T, Yan X, et al. Transcriptomic analysis reveals the parallel transcriptional regulation of UV-B-induced artemisinin and flavonoid accumulation in Artemisia annua L. Plant Physiol Biochem. 2021;163:189-200.

34. Stephenson MJ, Reed J, Brouwer B, Osbourn A. Transient expression in Nicotiana benthamiana leaves for triterpene production at a preparative scale. J Vis Exp. 2018(138).

35. Zhang Y, Zhou L, Tang K, Xu M, Miao Z. Matching is the dey factor to improve the production of patchoulol in the plant chassis of Marchantia paleacea. ACS Omega. 2020;5(51):33028-38.

36. Jefferson RA, Kavanagh TA, Bevan MW. GUS fusions: beta-glucuronidase as a sensitive and versatile gene fusion marker in higher plants. Embo J. 1987:6(13):3901-7.
37. Hellens RP, Allan AC, Friel EN, Bolitho K, Grafton K, Templeton MD, Karunairetnam S, Gleave AP, Laing WA. Transient expression vectors for functional genomics, quantification of promoter activity and RNA silencing in plants. Plant Methods. 2005;1:13.

38. Alejos-Gonzalez F, Qu G, Zhou LL, Saravitz CH, Shurtleff JL, Xie DY. Charac terization of development and artemisinin biosynthesis in self-pollinated Artemisia annua plants. Planta. 2011;234(4):685-97.

39. Grefen C, Donald N, Hashimoto K, Kudla J, Schumacher K, Blatt MR. A ubiquitin-10 promoter-based vector set for fluorescent protein tagging facilitates temporal stability and native protein distribution in transient and stable expression studies. Plant J. 2010;64(2):355-65.

40. Krebs M, Held K, Binder A, Hashimoto K, Den Herder G, Parniske M, Kudla J, Schumacher K. FRET-based genetically encoded sensors allow highresolution live cell imaging of $\mathrm{Ca}^{2+}$ dynamics. Plant J. 2012;69(1):181-92.

41. Shen Q, Zhang L, Liao Z, Wang S, Yan T, Shi P, Liu M, Fu X, Pan Q, Wang $Y$, et al. The genome of Artemisia annua provides insight into the evolution of Asteraceae family and artemisinin biosynthesis. Mol Plant. 2018;11(6):776-88

42. Farhi M, Marhevka E, Ben-Ari J, Algamas-Dimantov A, Liang Z, Zeevi V, Edelbaum O, Spitzer-Rimon B, Abeliovich H, Schwartz B, et al. Generation of the potent anti-malarial drug artemisinin in tobacco. Nat Biotechnol. 2011;29(12):1072-4

43. Madeira LM, Szeto TH, Henquet M, Raven N, Runions J, Huddleston J, Garrard I, Drake PM, Ma JK. High-yield production of a human monoclonal IgG by rhizosecretion in hydroponic tobacco cultures. Plant Biotechnol J. 2016;14(2):615-24.

44. Tabashnik BE, Sisterson MS, Ellsworth PC, Dennehy TJ, Antilla L, Liesner L, Whitlow M, Staten RT, Fabrick JA, Unnithan GC, et al. Suppressing resistance to Bt cotton with sterile insect releases. Nat Biotechnol. 2010;28(12):1304-7

45. Lu Y, Wu K, Jiang Y, Guo Y, Desneux N. Widespread adoption of Bt cotton and insecticide decrease promotes biocontrol services. Nature. 2012;487(7407):362-5.

46. Nuccio ML, Wu J, Mowers R, Zhou HP, Meghji M, Primavesi LF, Paul MJ, Chen X, Gao Y, Haque E, et al. Expression of trehalose-6-phosphate phosphatase in maize ears improves yield in well-watered and drought conditions. Nat Biotechnol. 2015;33(8):862-9.

47. Chen L, Li W, Li Y, Feng X, Du K, Wang G, Zhao L. Identified trans-splicing of YELLOW-FRUITED TOMATO 2 encoding the PHYTOENE SYNTHASE 1 protein alters fruit color by map-based cloning, functional complementation and RACE. Plant Mol Biol. 2019;100(6):647-58.

48. Sun W, Gao Z, Wang J, Huang Y, Chen Y, Li J, Lv M, Wang J, Luo M, Zuo K. Cotton fiber elongation requires the transcription factor GhMYB212 to regulate sucrose transportation into expanding fibers. New Phytol. 2019;222(2):864-81.

49. Vaghchhipawala Z, Rojas CM, Senthil-Kumar M, Mysore KS. Agroinoculation and agroinfiltration: simple tools for complex gene function analyses. Methods Mol Biol. 2011;678:65-76.

50. Bardor M, Loutelier-Bourhis C, Paccalet T, Cosette P, Fitchette AC, Vézina LP, Trépanier S, Dargis M, Lemieux R, Lange C, et al. Monoclonal C5-1 antibody produced in transgenic alfalfa plants exhibits a $\mathrm{N}$-glycosylation that is homogenous and suitable for glyco-engineering into humancompatible structures. Plant Biotechnol J. 2003;1(6):451-62.

51. Vidal JR, Gomez C, Cutanda MC, Shrestha BR, Bouquet A, Thomas MR, Torregrosa L. Use of gene transfer technology for functional studies in grapevine. Austral J Grape Wine Res. 2010;16(Suppl 1):138-51.

52. Daddy NB, Kalisya LM, Bagire PG, Watt RL, Towler MJ, Weathers PJ. Artemisia annua dried leaf tablets treated malaria resistant to ACT and i.v. artesunate: case reports. Phytomedicine. 2017;32:37-40.

53. Hassani D, Fu X, Shen Q, Khalid M, Rose JKC, Tang K. Parallel transcriptional regulation of artemisinin and flavonoid biosynthesis. Trends Plant Sci. 2020;25(5):466-76

54. Somssich M. A short history of the CaMV 355 promoter. PeerJ Prints 2019;7.

55. Aida R, Narumi T, Ohtsubo N, Yamaguchi H, Kato K, Shinmyo A, Shibata M. Improved translation efficiency in chrysanthemum and torenia with a translational enhancer derived from the tobacco alcohol dehydrogenase gene. Plant Biotechnol. 2008;25:69-75.

56. Debler JW, Henares BM, Lee RC. Agroinfiltration for transient gene expression and characterisation of fungal pathogen effectors in cool-season grain legume hosts. Plant Cell Rep. 2021;40(5):805-18. 
57. Peremarti A, Twyman RM, Gómez-Galera S, Naqvi S, Farré G, Sabalza M, Miralpeix B, Dashevskaya S, Yuan D, Ramessar K, et al. Promoter diversity in multigene transformation. Plant Mol Biol. 2010;73(4-5):363-78.

58. Mourrain $P$, van Blokland $R$, Kooter JM, Vaucheret $H$. A single transgene locus triggers both transcriptional and post-transcriptional silencing through double-stranded RNA production. Planta. 2007;225(2):365-79.

59. Yoo SD, Cho YH, Sheen J. Arabidopsis mesophyll protoplasts: a versatile cell system for transient gene expression analysis. Nat Protoc. 2007;2(7):1565-72.

60. Shepherd CT, Scott MP. Construction and evaluation of a maize (Zea mays) chimaeric promoter with activity in kernel endosperm and embryo. Biotechnol Appl Biochem. 2009;52(Pt 3):233-43.

61. Sultana MS, Frazier TP, Millwood RJ, Lenaghan SC, Stewart CN. Development and validation of a novel and robust cell culture system in soybean (Glycine max (L.) Merr.) for promoter screening. Plant Cell Rep. 2019;38(10):1329-45.
62. Kim MJ, Baek K, Park C-M. Optimization of conditions for transient Agrobacterium-mediated gene expression assays in Arabidopsis. Plant Cell Rep. 2009;28(8):1159-67.

63. Benfey PN, Chua NH. The cauliflower mosaic virus 35s promoter: combinatorial regulation of transcription in plants. Science. 1990;250(4983):959-66.

64. Adhikari PB, Han JY, Ahn CH, Choi YE. Lipid transfer proteins (AaLTP3 and AaLTP4) are involved in sesquiterpene lactone secretion from glandular trichomes in Artemisia annua. Plant Cell Physiol. 2019;60(12):2826-36.

\section{Publisher's Note}

Springer Nature remains neutral with regard to jurisdictional claims in published maps and institutional affiliations.
Ready to submit your research? Choose BMC and benefit from:

- fast, convenient online submission

- thorough peer review by experienced researchers in your field

- rapid publication on acceptance

- support for research data, including large and complex data types

- gold Open Access which fosters wider collaboration and increased citations

- maximum visibility for your research: over $100 \mathrm{M}$ website views per year

At BMC, research is always in progress.

Learn more biomedcentral.com/submissions 